\title{
The psychosis continuum: diagnosis and other phenotypes
}

\author{
H. J. Möller · P. Falkai
}

Published online: 18 January 2011

(c) The Author(s) 2011. This article is published with open access at Springerlink.com

The ongoing discussion on the revision of DSM and ICD is undulating between keeping to the tradition of diagnostic entities like schizophrenia or bipolar disorder or changing to new diagnostic constructs like the "Salience Syndrome". The current issue of the European Archives brings together some aspects along this ongoing discussion.

Läge et al. [1] address this question with their article "Combining the categorical and the dimensional perspective in a diagnostic map of psychotic disorders". In a prospective study, Rössler et al. [2] analyzed the interplay between psychosis and depression in the development of psychotic syndromes. This is of special interest to clinicians and researchers because the interaction between these two psychological subsyndromes has for a long time been underestimated sticking to categories like schizophrenia and depression.

Taking the course of illness into account, childhood adversity and development of a chronic mood disorder is specifically addressed by the paper of Angst et al. [3]. It stresses the necessity to perform a detailed biographical interview when assessing patients in order to estimate whether specific psychotherapy is needed. This is in accordance with a paper of Shavitt et al. [4] examining the impact of trauma and posttraumatic stress disorder on the treatment response of patients with obsessive compulsive disorder. These papers outline the bridge between early

\section{H. J. Möller}

Psychiatrische Klinik der Ludwig-Maximilians-Universität-

München, Nußbaumstraße 7, 80336 München, Germany

P. Falkai $(\bowtie)$

Abteilung für Psychiatrie und Psychotherapie, Universität Göttingen, von-Siebold-Straße 5, 37075 Göttingen, Germany e-mail: peter.falkai@medizin.uni-goettingen.de traumatic experiences and the later development of affective syndromes.

Looking at psychotic syndromes, gender-specific issues are of special interest. Along these lines, Wustmann et al. [5] point at gender-related features in persistent delusional disorders, which has not been discussed in the literature so far.

Speaking about boundaries between psychopathological subsyndromes, it is important to measure them in an adequate way. Bent-Hansen and Brech [6] tested the validity of different aspects of the Hamilton Depression Scale along these lines.

Finally, attention is drawn to the paper by Brisch et al. [7] analyzing the septal nuclei in schizophrenia and affective disorder morphometrically. One of the main findings is a selective reduction of neural density in the lateral septal nucleus in bipolar disorder. This stresses the importance of doing detailed analysis functionally and neuroanatomically when trying to understand neural circuitry underlying distinct psychopathological subsyndromes in severe mental disorder (e. g. Ziauddeen et al. [8]).

\section{H.-J. Möller \\ P. Falkai}

Open Access This article is distributed under the terms of the Creative Commons Attribution Noncommercial License which permits any noncommercial use, distribution, and reproduction in any medium, provided the original author(s) and source are credited.

\section{References}

1. Läge D, Egli S, Riedel M, Strauss A, Möller HJ (2010) Combining the categorical and the dimensional perspective in a diagnostic 
map of psychotic disorders. Eur Arch Psychiatry Clin Neurosci. doi:10.1007/s00406-010-0125-y

2. Rössler W, Angst J, Gamma A, Haker H, Stulz N, Merikangas KR, Ajdacic-Gross V (2010) Reappraisal of the interplay between psychosis and depression symptoms in the pathogenesis of psychotic syndromes: results from a twenty-year prospective community study. Eur Arch Psychiatry Clin Neurosci. doi:10.1007/s00406010-0123-0

3. Angst J, Gamma A, Rössler W, Ajdacic V, Klein DN (2010) Childhood adversity and chronicity of mood disorders. Eur Arch Psychiatry Clin Neurosci. doi:10.1007/s00406-010-0120-3

4. Shavitt RG, Valério C, Fossaluza V, da Silva EM, Cordeiro Q, Diniz JB, Belotto-Silva C, Cordioli AV, Mari J, Miguel EC (2010) The impact of trauma and post-traumatic stress disorder on the treatment response of patients with obsessive-compulsive disorder. Eur Arch Psychiatry Clin Neurosci 260:91-99

5. Wustmann T, Pillmann F, Marneros A (2010) Gender-related features of persistent delusional disorders. Eur Arch Psychiatry Clin Neurosci. doi:10.1007/s00406-010-0130-1
6. Bent-Hansen J, Bech P (2010) Validity of the definite and semidefinite Questionnaire version of the Hamilton Depression Scale, the Hamilton Subscale and the Melancholia Scale. Part I. Eur Arch Psychiatry Clin Neurosci. doi:10.1007/s00406-0100106-1

7. Brisch R, Bernstein HG, Dobrowolny H, Krell D, Stauch R, Trübner K, Steiner J, Ghabriel MN, Bielau H, Wolf R, Winter J, Kropf S, Gos T, Bogerts B (2010) A morphometric analysis of the septal nuclei in schizophrenia and affective disorders: reduced neuronal density in the lateral septal nucleus in bipolar disorder. Eur Arch Psychiatry Clin Neurosci. doi:10.1007/s00406-0100119-9

8. Ziauddeen H, Dibben C, Kipps C, Hodges JR, McKenna PJ (2010) Negative schizophrenic symptoms and the frontal lobe syndrome: one and the same? Eur Arch Psychiatry Clin Neurosci. doi: 10.1007/s00406-010-0133-y 